\title{
COVID-19 and chronic diabetes: the perfect storm for reactivation tuberculosis?: a case series
}

\author{
Genesis P. Aguillón-Durán ${ }^{1}$, Ericka Prieto-Martínez ${ }^{2,3}$, Doris Ayala', Juan García Jr. ${ }^{4}$, John M. Thomas III \\ Juan Ignacio García ${ }^{5}$, Brandon Michael Henry ${ }^{5}$, Jordi B. Torrelles ${ }^{5}$, Joanne Turner ${ }^{5}$, Eder Ledezma-Campos ${ }^{4}$ and \\ Blanca I. Restrepo ${ }^{1,4^{*}}$
}

\begin{abstract}
Background: The coronavirus disease 2019 pandemic is predicted to have a net negative effect on tuberculosis control, with an estimated excess of 6.3 million tuberculosis cases and 1.4 million deaths by 2025. Programmatic issues such as the lockdown of tuberculosis services affect all patients, while biosocial factors have a differential impact on an individual's risk for tuberculosis or adverse tuberculosis outcomes.

Case presentation: We report three Hispanic cases of incident tuberculosis (two males, 43 and 44 years old; one female, 49 years old) after resolution of coronavirus disease episodes. Coincidentally, all cases shared a common risk factor: a chronic history poorly controlled diabetes.

Conclusions: Our findings alert to the threat posed by the synergy between coronavirus disease and diabetes, on tuberculosis reactivation. In medium- to high-risk settings for tuberculosis, we recommend implementation of routine screening for latent tuberculosis infection in these cases, and preventive tuberculosis treatment in those who are positive.
\end{abstract}

Keywords: Tuberculosis, COVID-19, SARS-CoV-2, Diabetes mellitus, Type 2 diabetes, Diagnostic delays

\section{Background}

The coronavirus disease 2019 (COVID-19) pandemic is predicted to become a double-edged sword for tuberculosis (TB) control [1]. On the positive side, comprehensive preventive measures against COVID-19 such as self-quarantine, social distancing, and use of face masks is likely to reduce the spread of Mycobacterium tuberculosis. However, there is an anticipated net negative effect of COVID-19 on TB control, including an increase in the number of TB cases and deaths, and the proportion of

\footnotetext{
*Correspondence: Blanca.i.restrepo@uth.tmc.edu

${ }^{4}$ Department of Human Genetics, South Texas Diabetes and Obesity Institute, School of Medicine, University of Texas Rio Grande Valley, 1214 W Schunior, UTRGV-Edinburg Campus, Edinburg, TX 78541, USA Full list of author information is available at the end of the article
}

drug-resistant TB [1]. Two types of interrelated factors can contribute: the first type are programmatic issues that affect all TB patients in a community. These include the lockdown of TB diagnosis and treatment services, and the redirection of the already limited resources for national TB programs worldwide to address the urgency of the COVID-19 pandemic. A model estimated that between 2020 and 2025 there will be a global excess of active TB cases $(3.1-10.7 \%)$ and deaths $(4-16 \%)$ as a result of the COVID-19 pandemic, setting back global TB control efforts by at least 8 years [2].

The second type are biological or social factors that can contribute to the hypothesized bidirectional synergy between severe acute respiratory syndrome coronavirus 2 (SARS-CoV-2) and Mycobacterium tuberculosis [3]. original author(s) and the source, provide a link to the Creative Commons licence, and indicate if changes were made. The images or other third party material in this article are included in the article's Creative Commons licence, unless indicated otherwise in a credit line to the material. If material is not included in the article's Creative Commons licence and your intended use is not permitted by statutory regulation or exceeds the permitted use, you will need to obtain permission directly from the copyright holder. To view a copy of this licence, visit http://creativecommons.org/licenses/by/4.0/. The Creative Commons Public Domain Dedication waiver (http://creativeco mmons.org/publicdomain/zero/1.0/) applies to the data made available in this article, unless otherwise stated in a credit line to the data. 
First, both microbes primarily target the lung. Second, both share social risk factors (for example poverty, overcrowding, malnutrition, and poor access to healthcare), which increase the risk of disease transmission, progression, and poor TB treatment outcomes [4-6]. Third, both diseases share biological risks, such as male gender or diabetes. Diabetes increases the risk of TB development or adverse treatment outcomes, and is also a risk factor for more severe COVID-19 presentation and increases the risk of death [4, 7-9]. Fourth, there is reported immunosuppression in COVID-19 patients that would be expected to favor $M$. tuberculosis growth. These include reduction in $\mathrm{CD} 4$ and $\mathrm{CD} 8$ counts, functional exhaustion of these $\mathrm{T}$ cells [10] and heightened production of interleukin (IL)-10 in response to the viral infection [11], and the widespread, often unregulated and inappropriate use of immunosuppressive treatments (for example steroids, tocilizumab) in many countries [12]. Thus, the convergence of these biosocial factors would be expected to increase the risk of adverse outcomes for COVID-19 or TB. However, clinical evidence is still limited, albeit beginning to show support. The first published cohort of COVID-19 and TB provides examples of TB preceding, overlapping, or following COVID-19 infection [13]. Some studies have reported more severe TB disease, delayed recovery, and higher death in patients with both TB and COVID-19 [3, 4, 13-15]. Likewise, TB prevalence was higher among patients with severe COVID-19, when compared with nonsevere cases [3]. Thus, the need for integrated care of both types of diseases and, hence, knowledge of the individual risk factors that retro-feed on each other.

However, to date, the role of COVID-19 in boosting TB development is yet to be established [3]. We describe our findings in three individuals with newly diagnosed TB after recovery from COVID-19 (Table 1). These cases alert to the heightened risk for reactivation $\mathrm{TB}$ in patients recovering from COVID-19 with a chronic history of poorly controlled diabetes.

\section{Case presentation}

Two males (43 and 44 years old) and one female (49 years old) presented with signs and symptoms suggestive of active TB (Table 1) to the Centro Regional de Tuberculosis in Reynosa, Tamaulipas. They reported no pulmonary symptoms prior to the development of a COVID-19 episode 3-6 months ago. Their COVID-19 symptoms gradually disappeared, except for a persistent dry cough that gradually evolved into a productive cough (60 days ago for TR-241 and TR-247 and 90 days ago for TR-243), and was accompanied by dramatic weight loss and the reappearance of fever and chills $14-15$ days prior to reporting to the TB clinic. The three cases were diagnosed with pulmonary TB supported by abnormal chest $\mathrm{x}$-rays, positive acid-fast sputum smears ( $>10$ bacilli/field), and culture confirmation of $M$. tuberculosis spp. Their previous infection with SARS-CoV-2 was confirmed by positive anti-SARS-CoV-2 IgG titers. Informed consent was obtained from both participants as part of a parent study.

Besides COVID-19, other host factors or medical conditions influencing TB risk were examined (Table 1). A consistent finding was a chronic history of type 2 diabetes ( $\geq 5$ years) with poor glucose control (HbA1c $\geq 7.5 \%$ ). We cannot ascertain whether these were cases of primary progressive $\mathrm{TB}$ disease or of an incipient $\mathrm{TB}$ that was smoldering at the time of the COVID-19 diagnosis, or if this was a reactivation of a latent $M$. tuberculosis infection prompted by the COVID-19 episode. We consider the latter is more likely given that: (i) none of the cases reported pulmonary symptoms prior to the COVID-19 episode, (ii) two had no knowledge of previous exposure to a TB patient and one had a past exposure (Table 1), and (iii) there was a gradual appearance of a productive cough and the reemergence of fever and chills after the COVID-19 episode was resolved.

\section{Discussion}

Given that active TB disease takes weeks or months to develop, and that we are at an initial stage of the COVID19 pandemic, it is still early to evaluate the actual impact of COVID-19 on $M$. tuberculosis reactivation. Our findings alert us to be prepared in several ways.

First, diabetes and the SARS-CoV-2 infection are likely to retro feed each other to magnify the risk of $M$. tuberculosis reactivation to active TB. Diabetes is a major comorbidity for COVID-19 patients, resulting in poorer outcomes (RR 2.38, $p<0.001$ ), death (RR 2.12), and more severe disease (RR 2.45) [16]. Diabetes is also a wellestablished risk factor for TB [17, 18], and for adverse TB disease outcomes $[19,20]$. SARS-CoV-2 infection is associated with immunosuppression that persists past the COVID-19 episode, and likely synergizes with TB to favor primary or reactivation TB [21, 22]. Thus, we predict that the threefold higher risk of active TB development in diabetes patients is further amplified by SARS$\mathrm{CoV}-2$ infection.

Second, in our post-COVID-19 TB cases, the continuum of cough throughout both episodes masked the suspicion of an emerging TB and likely contributed to the significant delay in its diagnosis (60-90 days with productive cough) and high $M$. tuberculosis burden in their sputum ( $>10$ bacilli/field). TB diagnostic delays and high bacillary burden are associated with expanded community TB transmission and poorer TB prognosis [23], which is an added concern for post-COVID-19 TB cases. 
Table 1 Characteristics of newly diagnosed tuberculosis patients with a multiyear history of diabetes and a recent history of COVID-19

\begin{tabular}{|c|c|c|c|}
\hline & TR-241 & TR-243 & TR-247 \\
\hline \multicolumn{4}{|l|}{ Demographics $^{\mathrm{a}}$} \\
\hline Age in years, Sex & 43, male & 44 , male & 49 , female \\
\hline \multicolumn{4}{|l|}{ COVID-19 history } \\
\hline Timing prior to TB diagnosis & 3 months & 6 months & 4 months \\
\hline Anti-SARS-CoV-2 lgG at TB diagnosis ${ }^{b}$ & Positive & Positive & Positive \\
\hline \multicolumn{4}{|l|}{ Symptoms at the time of the COVID-19 episode: } \\
\hline Cough & Yes & Yes & Yes \\
\hline Fever, chills & Yes & Yes & Yes \\
\hline Fatigue & Yes & Yes & Yes \\
\hline Loss of smell and taste & Yes & Yes & Yes \\
\hline Shortness of breath & Yes & No & No \\
\hline Body aches & Yes & Yes & No \\
\hline \multicolumn{4}{|c|}{ Duration of TB signs and symptoms prior to reporting to the TB clinic (days) } \\
\hline Cough & 90 & 180 & 120 \\
\hline Productive cough & 60 & 90 & 60 \\
\hline Fever, chills & 14 & 15 & 14 \\
\hline Chest pain & 3 & $N / R$ & $N / R$ \\
\hline Weight loss & 60 & 60 & 60 \\
\hline Fatigue & $N / R$ & $\mathrm{~N} / \mathrm{R}$ & 30 \\
\hline \multicolumn{4}{|l|}{ TB diagnosis } \\
\hline Acid-fast bacilli smear grade (bacilli/field) & $>10$ & $>10$ & $>10$ \\
\hline M. tuberculosis culture ${ }^{c}$ & Positive & Positive & Positive \\
\hline \multicolumn{4}{|l|}{ TB risk factors and other medical conditions } \\
\hline Body mass index & 13.4 & 23.7 & 29 \\
\hline BCG vaccine & Yes & Yes & Yes \\
\hline HIV & Negative & Negative & Negative \\
\hline Smoking & No & No & No \\
\hline Alcohol excess and illicit drugs ${ }^{d}$ & No & Yes & No \\
\hline Type 2 diabetes & Yes & Yes & Yes \\
\hline Years with type 2 diabetes & $13 y$ & $5 y$ & $6 y$ \\
\hline $\mathrm{HbA1c}$ & $8.2 \%$ & $7.5 \%$ & $10.6 \%$ \\
\hline Fasting blood glucose (mg/dl) & 105 & 138 & 126 \\
\hline Diabetes medications ${ }^{\mathrm{e}}$ & Metformin & No & Glibenclamide metformin \\
\hline Other medical conditions & Peripheral neuropathy & None & High blood pressure \\
\hline \multicolumn{4}{|l|}{ History of past TB or TB exposure } \\
\hline Self-reported past exposure to a TB patient & No & No & Yes, $>2$ years ago \\
\hline Prior testing for latent TB infection & No & No & No \\
\hline Past history of active TB & No & No & No \\
\hline
\end{tabular}

N/R symptom not reported, TB tuberculosis, SARS-CoV-2 SARS coronavirus 2, COVID-19 coronavirus disease 2019, HIV Human immunodeficiency virus, HbA1C hemoglobin A1C

${ }^{a}$ All are Hispanic, White

${ }^{\mathrm{b}}$ Anti-SARS-CoV-2 IgG assay, Abbott Laboratories, Abbott Park, IL

${ }^{\mathrm{C}} M$. tuberculosis spp. identified with BioLine MPT64 Rapid, Standard Diagnostics, Korea

d TR-243: > 10 drinks and cocaine on weekends

e TR-247: metformin 1700 mg/d; TR-249: Metformin 500 mg/d and glibenclamide 2.5 mg/day

We recommend clinicians and public health workers to regard COVID-19 patients with diabetes and latent M. tuberculosis infection as having a heightened risk for TB. In high incidence settings for latent $M$. tuberculosis infection, patients with COVID-19 and diabetes should be alerted and educated to "think TB" in their 
post-COVID-19 recovery period, to reduce patient and healthcare provider diagnostic delays. In lowto medium-risk settings for $\mathrm{TB}$, screening for latent M. tuberculosis infection and treatment should be considered in diabetes patients recovering from COVID-19. Of note, current guidelines by the World Health Organization do not currently prioritize latent $M$. tuberculosis infection testing in diabetes patients [24]; however, this pre-COVID-19 recommendation should now be a consideration for those recovering from this viral infection. Finally, in developed countries where prophylactic TB treatment is administered, COVID-19 patients with diabetes comorbidity should be added to their targeted latent $M$. tuberculosis infection testing and treatment program.

\section{Conclusion}

Our findings alert to the heightened risk of $M$. tuberculosis reactivation among COVID-19 patients with a history of chronic and poorly controlled diabetes. In light of our findings, further research is needed to elucidate the underlying mechanisms and identify those who may be at highest risk, for targeted monitoring and management. In the meantime, we suggest a framework for new guidelines to prevent active TB in individuals affected with the COVID-19 and diabetes.

\section{Acknowledgements}

We thank the health professionals and administrators at the Secretaría de Salud de Tamaulipas, including Q. Cristela Resendez-Cardoso, Drs. Francisco Garcia-Luna Martinez and Ariel Mercado-Cárdenas (administration), and Mr. Jorge Perez-Navarro (logistics).

\section{Authors' contributions}

GPA-D: conceptualization, data collection, and curation; EP-M: data collection and curation; DA: data curation and analysis, project administration; JGJr: data curation and analysis; JMTIII, JIG, BMH: data curation and analysis, review and editing; JBT: conceptualization, resources, review and editing; JT: conceptualization, project administration, resources, review and editing; EL-C: project administration, review and editing; BIR: conceptualization, project administration, resources, original draft. All authors: reviewed the final version of the letter. All authors read and approved the final manuscript.

\section{Funding}

This work was supported by the National Institute of Aging (NIA) at the National Institutes of Health [P01-AG051428 to JT].

\section{Availability of data and materials}

The datasets used and/or analyzed during the current study are available from the corresponding author on reasonable request.

\section{Declarations}

\section{Ethics approval and consent to participate}

This study was approved by the institutional review boards in Mexico (SST/ SCAME/DCES/597/2017, Secretaría de Salud de Tamaulipas) and the United States (HSC-SPH-17-0990, University of Texas Health Houston). Written informed consent was obtained from patients and is available for provision to the journal on demand.

\section{Consent for publication}

Written informed consent was obtained from the patients for publication of this case report and any accompanying images. A copy of the written consent is available for review by the Editor-in-Chief of this journal.

\section{Competing interests}

The authors report no declarations of interest.

\section{Author details}

${ }^{1}$ School of Public Health, University of Texas Health Science Center at Houston, Brownsville Campus, Brownsville, TX 78520, USA. ${ }^{2}$ Secretaria de Salud de Tamaulipas, 88630 Reynosa, Tamaulipas, Mexico. ${ }^{3}$ Secretaria de Salud de Tamaulipas, 87000 Ciudad Victoria, Tamaulipas, Mexico. ${ }^{4}$ Department of Human Genetics, South Texas Diabetes and Obesity Institute, School of Medicine, University of Texas Rio Grande Valley, 1214 W Schunior, UTRGV-Edinburg Campus, Edinburg, TX 78541, USA. ${ }^{5}$ Population Health Program and Host Pathogens Interactions Program, Texas Biomedical Research Institute, San Antonio, TX 78229, USA.

Received: 19 April 2021 Accepted: 16 November 2021

Published online: 16 December 2021

\section{References}

1. Chen H, Zhang K. Insights into impact of COVID-19 epidemic on tuberculosis burden in China. Eur Respir J. 2020. https://doi.org/10.1183/13993 003.02710-2020.

2. McQuaid CF, McCreesh N, Read JM, Sumner T, CCW Group, Houben R, et al. The potential impact of COVID-19-related disruption on tuberculosis burden. Eur Respir J. 2020. https://doi.org/10.1183/13993003.01718-2020.

3. Visca D, Ong CWM, Tiberi S, Centis R, D'Ambrosio L, Chen B, et al. Tuberculosis and COVID-19 interaction: a review of biological, clinical and public health effects. Pulmonology. 2021;27:151-65.

4. Udwadia Z, Vora A, Tripathi A, Malu K, Lange C. COVID-19-tuberculosis interactions: when dark forces collide. Indian J Tuberc. 2020. https://doi, org/10.1016/j.jitb.2020.07.003.

5. Williamson EJ, Walker AJ, Bhaskaran K, Bacon S, Bates C, Morton CE, et al. Factors associated with COVID-19-related death using OpenSAFELY. Nature. 2020;584(7821):430-6.

6. Lonnroth K, Jaramillo E, Williams BG, Dye C, Raviglione M. Drivers of tuberculosis epidemics: the role of risk factors and social determinants. Soc Sci Med. 2009;68(12):2240-6.

7. Neyrolles O, Quintana-Murci L. Sexual inequality in tuberculosis. PLoS Med. 2009;6(12): e1000199.

8. Ronacher K, van Crevel R, Critchley JA, Bremer AA, Schlesinger LS, Kapur $A$, et al. Defining a research agenda to address the converging epidemics of tuberculosis and diabetes: part 2: underlying biologic mechanisms. Chest. 2017;152(1):174-80.

9. Baker MA, Harries AD, Jeon CY, Hart JE, Kapur A, Lonnroth K, et al. The impact of diabetes on tuberculosis treatment outcomes: a systematic review. BMC Med. 2011;9:81.

10. Diao B, Wang C, Tan Y, Chen X, Liu Y, Ning L, et al. Reduction and functional exhaustion of T cells in patients with coronavirus disease 2019 (COVID-19). Front Immunol. 2020;11:827.

11. Henry BM, Benoit SW, Vikse J, Berger BA, Pulvino C, Hoehn J, et al. The antiinflammatory cytokine response characterized by elevated interleukin-10 is a stronger predictor of severe disease and poor outcomes than the pro-inflammatory cytokine response in coronavirus disease 2019 (COVID19). Clin Chem Lab Med. 2021;59(3):599-607.

12. Ray A, Goel A, Wig N. Corticosteroids for treating mild COVID-19: opening the floodgates of therapeutic misadventure. QJM. 2021. https://doi.org/ 10.1093/qjmed/hcab138.

13. Tadolini M, Codecasa LR, Garcia-Garcia JM, Blanc FX, Borisov S, Alffenaar JW, et al. Active tuberculosis, sequelae and COVID-19 co-infection: first cohort of 49 cases. Eur Respir J. 2020. https://doi.org/10.1183/13993003. 01398-2020.

14. Magro P, Formenti B, Marchese V, Gulletta M, Tomasoni LR, Caligaris S, et al. Impact of the SARS-CoV-2 epidemic on tuberculosis treatment outcome in Northern Italy. Eur Respir J. 2020. https://doi.org/10.1183/13993 003.02665-2020 
15. Gao Y, Liu M, Chen Y, Shi S, Geng J, Tian J. Association between tuberculosis and COVID-19 severity and mortality: a rapid systematic review and meta-analysis. J Med Virol. 2020. https://doi.org/10.1002/jmv.26311.

16. Huang I, Lim MA, Pranata R. Diabetes mellitus is associated with increased mortality and severity of disease in COVID-19 pneumonia- a systematic review, meta-analysis, and meta-regression. Diabetes Metab Syndr. 2020;14(4):395-403.

17. Cadena J, Rathinavelu S, Lopez-Alvarenga JC, Restrepo BI. The re-emerging association between tuberculosis and diabetes: lessons from past centuries. Tuberculosis. 2019;116S:S89-97.

18. Harries AD, Kumar AM, Satyanarayana S, Lin Y, Zachariah R, Lonnroth K, et al. Addressing diabetes mellitus as part of the strategy for ending TB. Trans R Soc Trop Med Hyg. 2016;110(3):173-9.

19. Al-Rifai RH, Pearson F, Critchley JA, Abu-Raddad LJ. Association between diabetes mellitus and active tuberculosis: a systematic review and metaanalysis. PLoS ONE. 2017;12(11): e0187967.

20. Critchley JA, Restrepo BI, Ronacher K, Kapur A, Bremer AA, Schlesinger LS, et al. Defining a research agenda to address the converging epidemics of tuberculosis and diabetes: Part 1: epidemiology and clinical management. Chest. 2017:152(1):165-73.

21. Varghese J, Sandmann S, Ochs K, Schrempf IM, Frommel C, Dugas M, et al. Persistent symptoms and lab abnormalities in patients who recovered from COVID-19. Sci Rep. 2021;11(1):12775.

22. Shuwa HA, Shaw TN, Knight SB, Wemyss K, McClure FA, Pearmain L, et al. Alterations in T and B cell function persist in convalescent COVID-19 patients. Med. 2021;2(6):720-735.e4.

23. Getnet F, Demissie M, Assefa N, Mengistie B, Worku A. Delay in diagnosis of pulmonary tuberculosis in low-and middle-income settings: systematic review and meta-analysis. BMC Pulm Med. 2017;17(1):202.

24. Organization WH. Latent tuberculosis infection: updated and consolidated guidelines for programmatic management. Geneva: World Health Organization; 2018 .

\section{Publisher's Note}

Springer Nature remains neutral with regard to jurisdictional claims in published maps and institutional affiliations.

Ready to submit your research? Choose BMC and benefit from:

- fast, convenient online submission

- thorough peer review by experienced researchers in your field

- rapid publication on acceptance

- support for research data, including large and complex data types

- gold Open Access which fosters wider collaboration and increased citations

- maximum visibility for your research: over $100 \mathrm{M}$ website views per year

At BMC, research is always in progress.

Learn more biomedcentral.com/submissions 